\title{
Intracranial intraosseous hydatid cyst
}

\author{
Case report and review of the literature
}

\author{
Tahsin Erman, M.D., Metin Tuna, M.D., ísKender GöçER, M.D., Faruk íldan, M.D., \\ Mustafa Zeren, M.D., ANd Erdal Çetinalp, M.D. \\ Department of Neurosurgery, Çukurova University School of Medicine, Adana, Turkey
}

\begin{abstract}
Cerebral hydatidosis accounts for approximately 1 to $3 \%$ of all cases of hydatid disease. Generally, cerebral hydatid cysts are single lesions located in the watershed of the middle cerebral artery. Primary intracranial extracerebral hydatid cysts are extremely rare. Only $2 \%$ of hydatid cysts are localized in the skeleton, and of these 3 to $4 \%$ are found in the skull.

The authors describe the case of a 10-year-old boy who was admitted to their clinic with headache and unilateral focal epileptic seizures. Computerized tomography scanning revealed a right parietal intraosseous hydatid cyst. A case of cranial intraosseous hydatid disease is presented, and the differential diagnosis and treatment are discussed in the light of literature.
\end{abstract}

KEY WORDS • echinococcosis • hydatid cyst • skull

Hydatid disease is caused by infestation of larvae of the tapeworm Echinococcus granulosus. Although hydatid disease has been entirely eradicated in some countries, it remains a serious health problem in certain parts of the world and is endemic in the Middle East, Mediterranean, South America, and Australia., ${ }^{1,912,20,21}$

An adult tapeworm lives in the small intestine of definitive hosts, and its eggs contaminate water and food through ingestion of an intermediate host such as sheep, cattle, and humans. ${ }^{3,9,12}$ Humans are generally an incidental intermediate host, infected by the parasite frequently through the ingestion of the ova and rarely by inhalation. Hegzegant embryo becomes free after the digestion of ova in the gastrointestinal tract, and the resultant embryo most often settles in the liver through portal circulation. The embryo, which passes through the liver and crosses to the lymphatic system, enters the systemic circulation and may involve various organs, where it can cause hydatid disease. ${ }^{1,12,16,21}$ The most commonly affected organs are the liver and lung.

We present a case of primary cranial intraosseous hydatid cyst, and the differential diagnosis and treatment are discussed.

Abbreviation used in this paper: $\mathrm{CT}=$ computerized tomography.

\section{CASE REPORT}

Presentation. This 10-year-old boy was admitted to our clinic with a history of headache and left-sided focal motor seizures. The patient recounted a history of contact with the neighbor's dog.

Examination. Neurological and physical examinations demonstrated normal results. Analysis of peripheral blood samples showed findings within the normal range, except for the presence of an erthrocyte sedimentation rate of $40 \mathrm{~mm}$ in the 1st hour and eosinophilia. A cystic lesion was detected in the right parietal area on X-ray films (Fig. 1). Radiological examination of the other organ systems demonstrated normal findings. Axial CT scanning of the cranium revealed a large, single intraosseous cystic lesion in the right parietal area (Fig. 2).

Operation and Treatment. After the diagnosis was made, a parietal craniectomy was performed and the intraosseous cyst was totally removed without complication (Fig. 3). The patient was discharged 7 days after the operation and received albendazole treatment.

Histopathological evaluation of the cystic lesion confirmed the diagnosis of Echinococcus granulosus. Albendazole treatment was initiated at a dose of $10 \mathrm{mg} / \mathrm{kg}$ three times per day. The dose was repeated twice at 4-week intervals and was stopped 3 months postoperatively. During 


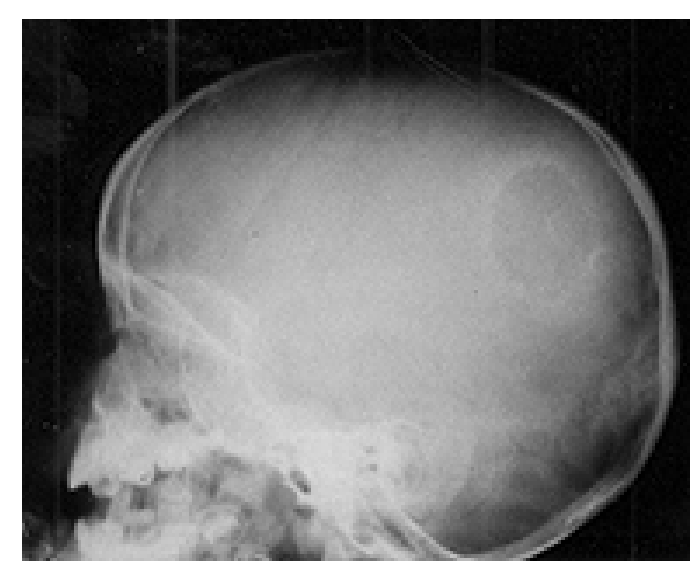

Fig. 1. Lateral x-ray film of the skull, revealing a large cystic lesion in the right parietal area.

a 12-month follow-up period, clinical, serological, and radiological examinations demonstrated no evidence that the hydatid disease involved any other organ system.

\section{DISCUSSION}

Hydatid disease is rarely localized in the brain and comprises only 1 to $3 \%$ of reported cases. ${ }^{1,5,7-9,13,14,21}$ A primary cyst is the most common type of hydatid disease and the primary lesion is always solitary, but secondary disease usually involves multiple cysts that develop after embolization of a cardiac cyst, which ruptures in the left ventricle; secondary cysts are also caused by spontaneous, traumatic, or surgically induced rupture of a primary central nervous system cyst. ${ }^{21}$

Cerebral hydatid cysts are usually located in the distribution of the middle cerebral artery because of the embolic nature of the infestation. ${ }^{2,6,9,19,22}$ Because the physiological blood flow of the brain is mainly supplied by the internal carotid artery system, the migration of larvae by way of the external carotid artery system is very rare. ${ }^{3,18}$

Primary intracranial extracerebral hydatid cysts have been reported but are extremely rare. They occur in three forms: $:^{2,3,17}$ 1) cranial-usually the osseous spongiosa is the first to be involved, with only $2 \%$ of the hydatid cysts localized to the skeleton and only $3-4 \%$ of these are in the skull; 2) cranial extradural - the extradural space may be infected by embolization of scolices or embryos via blood vessels, ${ }^{3}$ by extrusion of intracerebral cysts via healthy dura mater, ${ }^{4}$ or by erosion of osseous hydatid lesion into the extradural space; ${ }^{18}$ and 3) combined location - there may be simultaneous intracerebral, extradural, and osseous cysts. ${ }^{3}$

Computerized tomography scanning is more specific for identifying osseous lesions than other imaging modalities. In our case, cranial CT scans demonstrated the classical finding (intraosseous cystic lesion, solitary, regular contours, and spherical shape $e^{2,4}$ ). In particular eosinophilic granuloma, cystic fibrous dysplasia, and calvarial epidermoid tumor/cyst must be considered in the differential diagnosis of intraosseous hydatid cyst. Eosinophilic granuloma is usually solitary and involves the diploë. Computerized tomography scanning demonstrates a

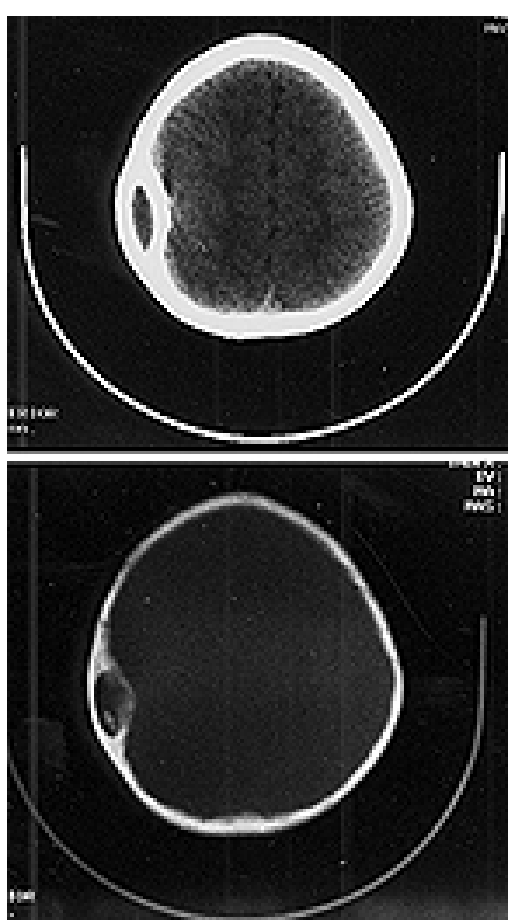

Fig. 2. Axial CT scans demonstrating intraosseous hydatid cyst in the right parietal area. Upper: Noncontrast scan. Lower: Bone window scan.

sharply marginated lytic skull defect more frequently involving the outer table than the inner table. ${ }^{10}$ The cystic form of fibrous dysplasia is usually homogeneously hypodense and typically has a smooth sclerotic border. An epidermoid tumor or cyst of calvarium has a sclerotic rim and lacks inner trabeculae. ${ }^{10}$ Less likely considerations include solitary metastasis, brown tumor, and plasmacytoma. Metastases and brown tumors are rarely solitary, and they are characteristically poorly marginated. Plasmacytoma may be solitary; it usually has a septated, bubbly, and irregulary marginated appearance. ${ }^{10}$

Despite the use of CT scanning, the differential diagnosis of intraosseous hydatid cyst may be difficult. The Casoni intradermal test, peripheral blood and cerebrospinal fluid eosinophilia, and serological tests may be helpful for the diagnosis of hydatid disease. As in our case, in which intracranial hydatid disease was present without any other

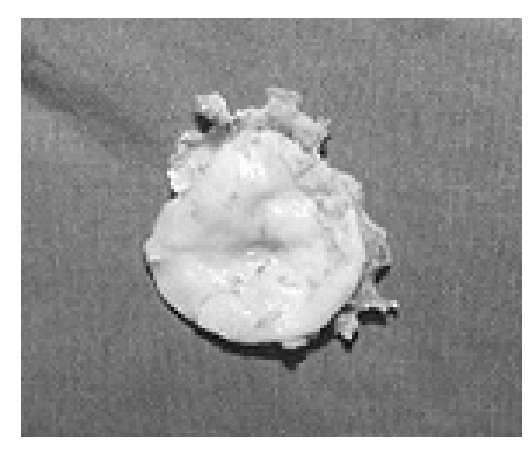

Fig. 3. Photograph of the excised right parietal hydatid cyst. 


\section{Cranial hydatid cyst}

foci or infestation, these tests may frequently yield negative findings. ${ }^{15}$ Examinations of the chest and abdominal organs with radiography and ultrasonography, respectively, must be performed routinely to exclude hydatid disease of lung and liver.

Surgical treatment is usually required when hydatid disease involves the central nervous system. Total resection of the cyst without rupture via the craniectomy is the recommended procedure. ${ }^{1,4,5,7,9,13}$ Extradural hydatid cysts of intraosseous origin, however, may be diffucult to excise completely because of their adherence to dura and osseous trabeculae. ${ }^{11}$ For this reason, if the cyst involves the extradural space, magnetic resonance imaging should be performed to obtain a diagnosis and plan the surgery. If the cyst ruptures intraoperatively, extensive irrigation of the surgical field with a hypertonic solution and a course of oral albendazole may help to prevent the recurrence.

Patients with intraosseous hydatid cysts should be treated with albendazole for at least 3 months and monitored for up to 12 months before they are considered cured.

Although primary cranial intraosseous hydatid cysts are extremely rare, hydatid disease must be considered in the differential diagnosis of intraosseous cystic lesion, especially in areas in which the disease is endemic.

\section{References}

1. Altınörs N, Bavbek M, Caner HH, et al: Central nervous system hydatidosis in Turkey: a cooperative study and literature survey analysis of 458 cases. J Neurosurg 93:1-8, 2000

2. Ba'assiri A, Haddad FS: Primary extradural intracranial hydatid disease: CT appearance. AJNR 5:474-475, 1984

3. Behari S, Banerji D, Phadke RV, et al: Multiple infected extradural parasellar hydatid cysts. Surg Neurol 48:53-57, 1997

4. Canbolat A, Onal C, Kaya U, et al: Intracranial extradural hydatid cysts: report of three cases. Surg Neurol 41:230-234, 1994

5. Ciurea AV, Vasilescu G, Nuteanu L, et al: Cerebral hydatid cyst in children. Experience of 27 cases. Childs Nerv Syst 11: 679-686, 1995

6. Cohen JE, Ginsberg HJ, Tsai EC, et al: Hydatid cyst and brain tumor in the same location. Case illustration. J Neurosurg 86: 312,1997

7. Çataltepe O, Çolak A, Özcan OE, et al: Intracranial hydatid cysts: experience with surgical treatment in 120 petients. Neurochirurgia 35:108-111, 1992

8. Erşahin Y, Mutluer S, Dermirtaş E, et al: A case of thalamic hydatid cyst. Clin Neurol Neurosurg 97:321-323, 1995
9. Erşahin Y, Mutluer S, Güzelbağ E: Intracranial hydatid cysts in children. Neurosurgery 33:219-225, 1993

10. Grossman CB: Magnetic Resonance Imaging and Computed Tomography of the Head and Spine, ed 2. Baltimore: Williams \& Wilkins, 1996, pp 549-653

11. Guo HR, Lu YJ, Bao YH, et al: Parasellar epidural hydatid cysts. Neurosurgery 32:662-665, 1993

12. Kazez K, Şahin M, Vatansev C, et al: Experimentally developed secondary echinococcosis in pleural and peritoneal cavities and the utility of serological tests during the follow up. Turk J Med Sci 30:101-107, 2000

13. Lunardi P, Missori P, Di Lorenzo N, et al: Cerebral hydatidosis in childhood: a retrospective survey with emphasis on longterm follow up. Neurosurgery 29:515-518, 1991

14. Nurchi G, Floris F, Montaldo C, et al: Multiple cerebral hydatid disease: case report with magnetic resonance imaging study. Neurosurgery 30:436-438, 1992

15. Pinon JM, Sulahian A, Remy G, et al: Immunological study of hydatidosis. I. Evaluation of immunoelectrodiffusion tests and enzyme-linked immunoelectrodiffusion assay (ELIEDA) in human hydatidosis. Am J Trop Med Hyg 28:318-319, 1979

16. Saidi F: Surgery of Hydatid Disease. Philadelphia: WB Saunders, 1976

17. Samiy E, Zadeh FA: Cranial and intracranial hydatidosis with special reference to roentgen-ray diagnosis. J Neurosurg 22: 425-433, 1965

18. Sardhana VR, Dharker SR, Mittal RS,et al: Multiple intracranial hydatid cysts. Neurol India 39:205-208, 1991

19. Sierra J, Oviedo J, Bertheir M, et al: Growth rate of secondary hydatid cysts of the brain. Case report. J Neurosurg 62: 781-782, 1985

20. Singounas EG, Leventis AS, Sakas E, et al: Successful treatment of intracerebral hydatid cysts with albendazole: case report and review of the literature. Neurosurgery 31:571-574, 1992

21. Turgut M, Benli K, Eryilmaz M: Secondary multiple intracranial hydatid cysts caused by intracerebral embolism of cardiac echinococcosis: an exceptional case of hydatidosis. Case report. J Neurosurg 86:714-718, 1997

22. Vaquero J, Jimenez C, Martinez R: Growth of hydatid cysts evaluated by CT scanning after presumed cerebral hydatid embolism. Case report. J Neurosurg 57:837-838, 1982

Manuscript received May 16, 2001.

Accepted in final form June 12, 2001.

Address reprint requests to: Tahsin Erman, M.D., Çukurova University School of Medicine, Department of Neurosurgery, Balcal1Adana 01330, Turkey. email: dr_erman@yahoo.com. 